\title{
Sustained negative contrast obtained following signaled shifts in sucrose reinforcement
}

\author{
M. E. SHANAB, J. DOMINO, and G. STEINHAUER \\ California State University, Fresno, California 93740
}

\begin{abstract}
A three-phase study was run in which 44 rats first received either 2-sec or 20-sec access to $18 \%$ sucrose reward. Then all subjects received 2 -sec access to the reward, with half of each main group receiving a tone along with the reward. Following a 2-month rest period, the rats were tested again under the same reinforcement conditions as in the first shift phase. Strong NCEs were exhibited in both shift phases only by those subjects that were exposed to the tone.
\end{abstract}

Several studies have been carried out in our laboratory investigating the general hypothesis that the introduction of a discriminative stimulus $(\mathrm{SD})$ at the time of shift in reinforcement conditions enhances the emergence of contrast. The present study deals with negative contrast as a function of a downward shift in sucrose reward when the shift is introduced either in the presence or in the absence of a discriminative tone stimulus in the runway. In runway situations, a negative contrast effect (NCE) is said to have taken place if subjects shifted from a larger to a smaller reward run significantly slower than control subjects receiving the smaller reward all the time. Conversely, when upshifted subjects run faster than their controls, a positive contrast effect (PCE) is said to have taken place. In the Skinner box, when the schedule associated with one component (varied component) is decreased while the schedule associated with the other (constant component) remains unchanged, the response rate in the constant component typically increases relative to its baseline in a direction opposite to that in the varied component. This phenomenon has been referred to as positive behavioral contrast (PBC). Negative behavioral contrast (NBC) occurs when responding in the constant component decreases while responding in the varied component increases following a shift to a denser schedule in the varied component.

At present, there are two theories that seem to deal adequately with either one or both sides of contrast. Additivity theory, which was developed in the operant tradition, proposes that positive contrast occurs as a result of the summation of classical and operant conditioning processes. Thus, PBC occurs when the discriminative stimulus (constant component) becomes classically conditioned to the reinforcer following a decrease in the reinforcement schedule in the varied component. Since the response has already been operantly conditioned, an increase in the response rate is observed,

This study was presented in part at the American Psychological Association meeting, Los Angeles, 1981, by Orna Molayem. reflecting the summation of operant and classical conditioning processes. Additivity theory does not deal with NBC. However, an attempt will be made later to modify additivity theory so as to account for NBC.

Neo-Hullian theory (e.g., Amsel, 1967; Spence, 1956) was developed to deal primarily with runway situations. According to Spence's (1956) theory, instrumental learning is mediated by the classically formed $\mathrm{r}_{\mathrm{g}}$ - $\mathrm{s}_{\mathrm{g}}$ mechanism. Specifically, Spence suggested that the subject learns to make conditioned goal responses $\left(r_{g}\right)$ in the goal area that, through backward generalization, are evoked at the start. The $r_{g}$ responses produce their own interoceptive stimuli, which become conditioned to the instrumental response. The stimuli in the alley evoke the $r_{g}-s_{g}$ mechanism, which not only triggers and directs the behavior of the subject but also determines the strength of the response.

Spence (1956) proposed that the $r_{g}-s_{g}$ was the underlying mechanism for the incentive motivation construct $(\mathrm{K})$ that combined multiplicatively with habit strength $(\mathrm{H})$ and additively with drive (D) to determine reaction potential (E). Such theorizing could explain both positive and negative contrast effects if it could be assumed that the magnitude of reward exerts a relative rather than an absolute effect on performance, or in Spence's terms, if the old $\mathrm{K}$ associated with the runway stimuli (and the appropriate reward) and the new $\mathrm{K}$ associated with the discriminative stimulus (and the new reward) summate algebraically to produce either an increase or a decrease in response rate relative to controls (cf. Shanab \& Cavallaro, 1973).

Amsel's (1967) theory makes more explicit predictions concerning downshifts in reinforcement conditions. According to Amsel, subjects shifted from a large to a smaller reward magnitude experience an emotional state of frustration that leads to avoidance responses that interfere with the ongoing approach response. These disruptive frustration responses lead to a decrement in the performance of the downshifted subjects relative to their controls. Amsel proposed an $\mathrm{r}_{\mathrm{F}}-\mathrm{s}_{\mathrm{F}}$ mechanism analogous to the $\mathrm{r}_{\mathrm{g}}-\mathrm{s}_{\mathrm{g}}$ mechanism 
that mediates the instrumental response, which, in this case, would be an avoidance response.

The evidence for NCE based on downshifts in sucrose reward is quite meager. Early studies in which either magnitude or concentration of liquid sucrose reward was downshifted led to nonsignificant results (Goodrich, 1962; Homzie \& Ross, 1962; Ison \& Rosen, 1968). Even when both magnitude and concentration were downshifted simultaneously, no NCE was obtained (Barnes \& Tombaugh, 1973; Flaherty, Riley, \& Spear, 1973; Ison \& Rosen, 1968). In a more recent study, Shanab, Young, and France (1975) failed to obtain an NCE in two separate studies in which liquid sucrose was downshifted. However, in a repeated-shifts design, which involves returning subjects to conditions previously experienced, Shanab, France, and Young (1976) found a significant NCE. This was explained in terms of enhanced frustration. Benefield, Oscos, and Ehrenfreund (1974) proposed that experience with frustration was a sufficient condition for both NCE and PCE and that more than one shift is required for subjects to experience frustration. An alternative explanation would be to assume that the repeated-shifts design increases the salience of the reinforcement shift conditions. More recently, Shanab, Molayem, Gordon, and Steinhauer (1981) reported a significant NCE based on a downshift in magnitude of water reward when the shift was made in the presence of a discriminative tone stimulus. It is conceivable that, among other things, the tone could have increased the salience of the shift condition and led to the emergence of an NCE.

The present study investigated the effects of a downshift in liquid sucrose reward when the shift was made in either the presence or the absence of a discriminative stimulus. It was predicted that an NCE would be obtained only when the shift was accompanied by a discriminative stimulus. The study also investigated the long-term effects of the downshift by allowing subjects to rest for 2 months following the completion of the shift phase and then testing them again under the same shift conditions as before. According to Amsel's (1976) theory, NCE would persist because the stimuli in the alley would evoke the $r_{F}-S_{F}$ mechanism that had already been conditioned to avoidance responses.

\section{METHOD}

\section{Design}

A three-phase study was run. In Phase 1, two independent groups of 22 subjects each received either $2 \mathrm{sec}$ access (smallreinforcement condition, S), or 20 -sec access (large-reinforcement condition, L) to $18 \%$ sucrose solution. In Phase 2, all subjects received the small reward, and half of the subjects received a tone (T) along with the reward and the other half did not. Thus, a 2 by 2 design was used in Phase 2, yielding the following four groups: SST, SS, LST, and LS. Phase 3 was identical to Phase 2, except that it was started after a 2-month rest period following the end of Phase 2.

\section{Subjects}

The subjects were 44 male albino rats of the Sprague-Dawley strain, approximately 90 days old at the beginning of the experiment.

\section{Apparatus}

The same $1.5-\mathrm{m}$ redwood runway described by Shanab et al. (1981) was used. A $71-\mathrm{dB}$ tone with a frequency of $247 \mathrm{~Hz}$ was used.

\section{Procedure}

The subjects were housed individually and handled approximately $2 \mathrm{~min} /$ day for 15 days. After the handling period, the subjects received a 23.5-h water-deprivation schedule for 5 days and then were placed on 23.75 -h deprivation, which continued for the remainder of the study. Following 15 days of water deprivation, the subjects were given 7 days exposure to the runway. During the first 4 days of exploration, the subjects were allowed to explore the apparatus with both guillotine doors left open and the equipment turned off. At this time, each subject was also familiarized with $18 \%$ sucrose solution outside the apparatus. For the next 3 days, the subjects were given exploration with the equipment turned on and the guillotine doors operating as during a regular trial. During the next 2 days, operant levels were taken and the subjects were randomly assigned to two groups.

On Days $1-4$ of Phase 1 , each subject received 1 trial/day. On Day 5 and for the remainder of the experiment, each subject received 2 trials/day. Subjects assigned to the small-reinforcement condition received 2 -sec access and subjects in the largereinforcement condition received $20 \mathrm{sec}$ access to an $18 \%$ sucrose solution. The subjects were run in squads of 12 with an intertrial interval of $10 \mathrm{~min}$. Phase 1 lasted 20 days.

In Phase 2, subjects in each condition were matched in terms of their mean asymptotic running speeds in Phase 1 and were divided into four equal groups. All subjects received the smallreinforcement condition, with half of each main group receiving the tone stimulus along with the reward. For Days 1-4 of Phase 2, the tone was presented when the last (goal) photobeam was broken. On Day 5 and for the remainder of the experiment, the tone was presented when the first (start) photobeam was triggered. Phase 2 lasted 20 days.

Following Phase 2 , the rats were placed on ad tib food and water for 2 months, after which they were placed on a $23.75-\mathrm{h}$ deprivation schedule for 15 days. Then Phase 3 was started. In Phase 3, the rats received the same conditions they had received in Phase 2.

\section{RESULTS}

All analyses are based on speed measures (in meters per second) over blocks of four trials each.

Since all three speed measures were almost identical, both graphically and statistically, only the run measure will be presented here (see Figure 1). A 2 by 2 by 6 analysis of variance test with magnitude shift and stimulus conditions (i.e., presence or absence of the tone) as the between-subjects factors was performed over the last six blocks of Phase 2. Both the main effect of magnitude shift $[\mathrm{F}(1,40)=14.48, \mathrm{p}<.005]$ and the Magnitude Shift by Stimulus Condition interaction $[F(1,40)=4.75$, $\mathrm{p}<.035]$ were significant. Neither the main effects of stimulus condition $[F(1,40)=2.00, p>.05]$ nor the blocks effects $[F(5,200)=1.45, p>.05]$ were significant. The interaction of blocks with the magnitude shift was not significant $[F(5,200)=1.16, p>.05]$. However, the interactions of blocks with the stimulus condition $[F(5,200)=2.18, p<.06]$ and with the two 


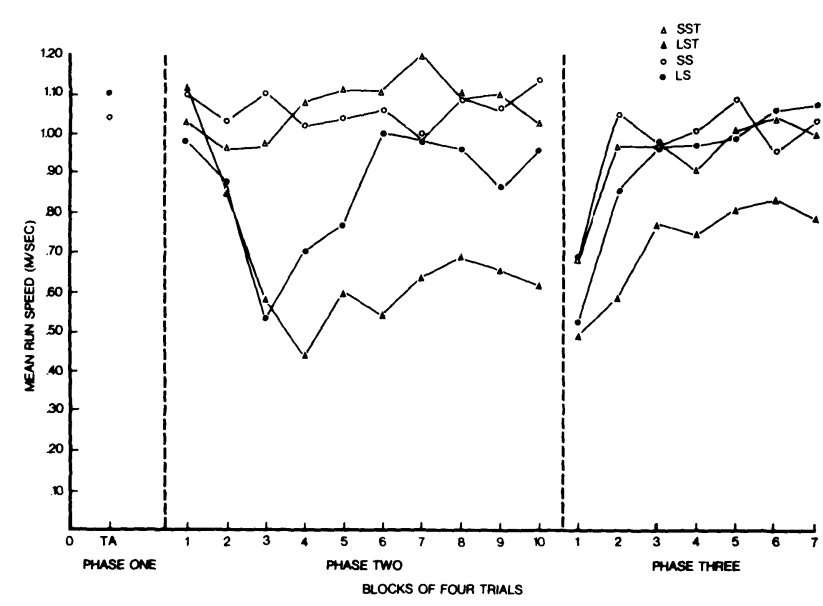

Figure 1. Mean run speed (in meters per second) as a function of a downshift in $18 \%$ sucrose reward when the shift was of was not accompanied by a tone.

main effects $[F(5,200)=2.12, p<.06]$ approached significance. Tests of simple effects yielded a highly significant NCE when the tone accompanied the delivery of the reward $[F(1,40)=17.87, p<.001]$ but not when the downshift was made in the absence of the tone $[F(1,40)=1.33, p>.05]$. Essentially the same results were obtained when a simple 2 by 2 analysis of variance test was performed over Blocks 3-10. While the stimulus conditions effect was not significant $(F<1)$, both the magnitude shift $[F(1,40)=13.27, p<.001]$ and the Magnitude Shift by Stimulus Conditions interaction effects were significant $[F(1,40)=5.78, p<.05]$. The results of simple main effects test revealed a highly significant NCE when the tone accompanied the downshift $[F(1,40)=18.28, p<.001]$ but not when the tone was absent $(\mathrm{F}<1)$.

A 2 by 2 by 5 analysis of variance test was performed over the last five blocks of trials in Phase 3 (which was initiated after a 2 -month rest period), yielding a significant effect due to stimulus conditions $[F(1,40)=4.54$, $\mathrm{p}<.04]$ but a nonsignificant magnitude shift effect $[F(1,40)=2.58, p>.05]$. The interaction of the two main effects was not significant $[F(1,40)=2.49$, $\mathrm{p}>.05]$. Similarly, neither the blocks effect $[F(5,160)=1.72, p>.05]$ nor the interaction of blocks with either main effect (both $F_{s}<1$ ) was significant. Moreover, the triple interaction was not significant $[F(5,160)=1.41, p>.05]$. Tests of simple main effects revealed a significant NCE for the subjects that were exposed to the tone during receipt of the downshifted reward magnitude $[F(1,40)=5.05, p<.05]$ but not for those subjects that were downshifted in the absence of the tone $(F<1)$. The NCE was still present on the last block of Phase $3[F(1,40)=16.08, p<.001]$ when the tone accompanied the downshift, but not when it $\operatorname{did} \operatorname{not}(\mathrm{F}<1)$.

\section{DISCUSSION}

The finding of a significant NCE only when the downshift in sucrose reward was accompanied by a discriminative stimulus gives strong support to the hypothesis tested. The findings are in agreement with the few sucrose studies that reported a significant NCE (cf. Shanab, Domino, \& Melrose, 1977; Shanab et al., 1976). The results also agree with the water study cited earlier, in which a significant NCE was reported when the downshift in water reward was accompanied by a discriminative stimulus (Shanab et al., 1981). A significant NCE was reported in two other water studies (Shanab \& Spencer, 1978; Spencer \& Shanab, 1979) that used superimposed delay. When a downshift was made in water reward under immediate (nondelay) conditions, no significant NCE was obtained (Spencer \& Shanab, 1979). The procedures used in the previous studies apparently produced a similar outcome. It is conceivable that using repeated shifts (Shanab et al., 1976), superimposed delay (Shanab \& Spencer, 1978; Shanab et al., 1977; Spencer \& Shanab, 1979), and a discriminative stimulus (Shanab et al., 1981) helps to increase the salience of the downshift in reinforcement conditions. In Amsel's (1967) terms, the increased salience strengthens the conditioning of the frustrative stimuli to responses that interfere with the ongoing response.

As noted earlier, additivity theory does not deal explicitly with negative contrast. Additivity theory attributes PBC to the summation of a classical "excitatory" process (reflected in the stimulus-reinforcer relation), and an operant process (reflected in the response-reinforcer relation). Additivity theory can easily accommodate negative contrast by assuming that a classical "inhibitory" process summates with the operant process. Rachlin (1973) had earlier attributed negative contrast to the reduction in the rate of instrumental responses by inhibitory responses produced by the stimulus-reinforcer relation. Other investigators have also used the notion of inhibition to account for negative contrast (cf. Hearst \& Jenkins, 1974; Terrace, 1972).

The permanence of the NCE observed in this study is striking, since the more reliable NCE obtained with downshifts in solid-food reward is typically short-lived (cf. Capaldi, 1972). The present study differs from previous studies in that the shift in reinforcement conditions was accompanied by a salient discriminative stimulus. According to Amsel's (1967) theory, the discriminative stimulus that has been conditioned to the frustration mechanism, ${ }^{r} F^{-s}$, during the first shift phase will continue to evoke the same mechanism 2 months later as long as reinforcement conditions remain unchanged and no extinction of the rF-sF mechanism takes place. In other words, the discriminative stimulus would evoke the $\mathrm{rF}_{\mathrm{F}}^{-\mathrm{s} F}$ mechanism, which in turn would lead to responses that are disruptive or otherwise interfere with the goal-oriented response. Unlike previous studies that have not used an external stimulus to accompany the downshift, the discriminative stimulus in this study probably helped to strengthen and maintain the conditioning of the frustration mechanism to interfering or avoidance responses.

An obvious conclusion from this study is that when the operant and discrete-trial procedures are made more similar by introducing an $\mathrm{S}^{\mathrm{D}}$ at the time of the shift, comparable results are obtained.

\section{REFERENCES}

Amsel, A. Partial reinforcement effects on vigor and persistence: Advances in frustration theory derived from a variety of withinsubjects experiments. In K. W. Spence \& J. T. Spence (Eds.), The psychology of learning and motivation (Vol. 1). New. York: Academic Press, 1967. 
Barnes, W., \& Tombaugh, J. N. Another failure to obtain negative contrast following reductions in sucrose reward. Psychological Reports, 1973, 33, 801-802.

Benefield, R., Oscos, A., \& Ehrenfreund, D. Role of frustration in successive positive contrast. Journal of Comparative and Physiological Psychology, 1974, 86, 648-651.

Capaldi, E. J. Successive negative contrast effects: Intertrial interval, type of shift, and four sources of generalization decrement. Journal of Experimental Psychology, 1972, 96, 433-438.

Flaherty, C. F., Riley, E. P., \& Spear, N. E. Effects of sucrose concentration and goal units on runway behavior in the rat. Learning and Motivation, 1973, 4, 163-175.

Goodrich, K. P. Supplementary report: Running speed as a function of sucrose concentration in a prior free-drinking period. Psychological Reports, 1962, 11, 528-530.

HeARST, E., \& Jenkins, H. M. Sign tracking: The stimulus reinforcer relation and directed action. Austin, Tex: Psychonomic Society, 1974.

Homzie, M. J., \& Ross, L. E. Runway performance following a reduction in the concentration of a liquid reward. Journal of Comparative and Physiological Psychology, 1962, 55, 1029-1033.

Ison, J., \& Rosen, A. Extinction and reacquisition performance as a function of sucrose solution rewards and number of acquisition trials. Psychological Reports, 1968, 22, 375-379.

RACHLIN, H. Contrast and matching. Psychological Review, 1973, 80, 217-234.

Shanab, M. E., \& Cavallaro, G. Transfer between nonreward and delay of reward following minimal acquisition training. Animal Learning \& Behavior, 1973, 1, 179-182.
Shanab, M. E., Domino, J., \& Melrose, S. The effects of shifts in delay of liquid sucrose reward in thirsty rats. Bulletin of the Psychonomic Society, 1977, 10, 287-290.

Shanab, M. E., France, J., \& Young, T. Positive and negative contrast effects obtained following shifts in liquid sucrose rewards in thirsty rats. Animal Learning \& Behavior, 1976, 4, 9-12.

Shanab, M. E., Molayem, O., Gordon, A. C., \& Steinhauer, G. Effects of signaled shifts in liquid reinforcement. Bulletin of the Psychonomic Society, 1981, 18, 263-266.

Shanab, M. E., \& Spencer, R. Positive and negative contrast effects obtained following shifts in delay of water reward. Bulletin of the Psychonomic Society, 1978, 12, 199-202.

Shanab, M. E., Young, T., \& France, J. Negative contrast as a function of downshifts in magnitude of sucrose concentrations in thirsty rats. Bulletin of the Psychonomic Society, 1975, 5, 381-384.

SPENCE, K. W. Behavior theory and conditioning. New Haven, Conn: Yale University Press, 1956.

Spencer, R. E., \& Shanab, M. E. Contrast effects as a function of delay and shifts in magnitude of water reward in thirsty rats. Bulletin of the Psychonomic Society, 1979, 13, 93-96.

TERRACE, H. S. By-products of discrimination learning. In G. H. Bower (Ed.), The psychology of learning and motivation (Vol. 5). New York, Academic Press, 1972.

(Received for publication January 28, 1982.) 